\title{
Yasin Aktay, Postmodern Kavşakta Din ve Sivil Toplum
}

(İstanbul: Tezkire Yayınevi, 2015) 422 s.

Yasin Aktay'ın incelediğimiz bu çalışması din olgusu ve sivil toplum kavramına dair tarihsel arka plan ışı̆̆ında okuyucuya geniş perspektif sunan bir kitap. Özellikle modernizm-postmodernizm ikiliği üzerinden kurucu sosyologların din olgusuna ilişkin yaklaşımları ve çağdaş dönemde ortaya konulan açlımlar dini anlama biçimimize boyut kazandırırken yeni tartışma alanlarına da kapı aralıyor. Kentleşmiş, çoğulcu, küresel ve postmodern dünyada dinin yeri, gelenek-değişim, din sosyolojisi-dini sosyoloji, teoloji-antropoloji gibi ikilikler ve sivil toplum devlet ilişkisi kitabın ele aldığı temel konular.

\section{Bilgi ve Deneyim}

Yazar kitaba Maide suresinin tarihsel ve toplumsal sürecin temel yasalarına 1şık tutan 48 . ayeti ve her bir topluluk için iyiliği emretme kötülükten sakındırmaya dair sorumluluğu hatırlatan Ali İmran suresi 104-110 ayetleriyle giriş yapıyor. Bir iki yerde yine ayetlere göndermede bulunuyor. "Kalpsiz Dünyanın Kalbi" başlıklı münhasır bir bölümde tamamen teolojik bir dil ve üslupla Hz. Peygamber' in şahsiyetini ele alıyor, onu beşeri sınırlar içinde mümkün dünyanın rol modeli olarak sunuyor. Yer yer tartışmalarda İslam'ın asıl mesajının ne olduğunu veya neyin İslam'a ters olduğunu vurguluyor. K1saca yazar inanç dünyasını metne açıkça yansıtıyor. Türkiye'de ilahiyatçıların toplumda yerleşik olan inançla bağlarını, bir diğer ifadeyle bilgi ile deneyim ilişkisini tartıştığı bölümde yazar Tanrı bilgisi iddiasının, -Kartezyen bilme eylemi mesafeyi gerektirdiğinden- varlıktan kaçınılmaz biçimde kopukluğa yol açacağına dair Heidegger'den alıntı yapıyor. Heidegger, ilahiyat bilgisinin varlıkla kurulan doğrudan duygulanım zeminini ortadan kaldırdığını öne sürüyor. Hatta kendi dinsizliğinin Tanrı'ya ilahiyatçılardan daha yakın olduğunu söylüyor (s. 155). Aktay, benzer şekilde Seyyid Kutup'a da göndermede bulunarak dinsel deneyim ile dini bilgi arasındaki kopmaz ilişkinin altını çiziyor.

Aktay'ın yürüttüğü bu tartışma aslında inancın, deneyimin ve duygu dünyasının bilimsel yaklaşımı ne ölçüde belirlediği üzerine epistemoloji tartışmalarına ışık tutuyor. Comte, Marx, Weber ve 
Durkheim gibi kurucu sosyologların din olgusuna yaklaşımlarındaki kategorik karşıtlığı eleştiren Aktay, neticede tüm dinlerin tek bir kategoride -insanın veya toplumun maddi gerçekliğinin birer yanıltıcı yansımalarından ibaret- görüldügüünü bu karşıtlığın da dini anlamayı imkânsızlaştırdığını ortaya koyuyor. Fakat diğer yandan yukarıda değindiğimiz üzere yazarımızın birçok noktada bilinçli bir şekilde dinsel motivasyonunu ve değer dünyasını sosyolojik perspektifine ş̧ık tuttuğunu görüyoruz. Nasıl ki kurucu sosyologlar değer dünyalarını bilimsel analizlerine belli ölçülerde yansıtmışlarsa aynı tutumu Aktay bu kez tersten tekrarlamış oluyor. Weber'in "Meslek Olarak Bilim" adlı meşhur makalesinde vurguladığı gibi inançtan, değer yargılarından ve öznel ön kabullerden bağımsız saf bir bilimin var olduğu fikri kuşkusuz oldukça naiftir. Dolayısıyla burada vurgulamak istediğimiz nokta deneyimin bilginin alanı dâhilinde tartışılmasına imkân verecek bir epistemolojik açılıma ihtiyaç duyduğumuz gerçeğidir. Alparslan Açıkgenç'in Bilgi Felsefesi adlı çalışmasında giriş mahiyetinde tartışmaya açtığı, özellikle duygu epistemolojisi başlığı altında değindiği sorunun bizi metodolojik ve epistemolojik bir çıkış yoluna zorladığının altını çizmektir.

\section{Modernizm Postmodernizm ve Din}

Aktay kitabın ilk bölümlerinde modernizm, postmodernizm ekseninde din ve toplumsal değişim, dini çoğulculuk, dini otorite, küresel anomi gibi başlıklar üzerinden tartışma yürütüyor.

Aktay, Postmodern duruma ilişkin yaygın eleştirel yaklaşımın tersine -fakat o boyutu da hesaba katarak- sunabileceği firsatlara dikkat çekiyor. Postmodern durum Aktay'a göre her şeyden önce bir kavşakta olma halidir ve bu kavşakta çok farklı tercihler yapabilme özgürlüğü sunar. Onun bu yorumu esasında Müslümanlar açısından kavrama ilişkin yaygın sinik tutumu kırmaya yönelik bir hamle olarak görülebilir. Bu aynı zamanda yazarın -islamcılık tartışmalarında da görüldüğü üzere- her koşulda israrla sürdürmeye çalışttğı iyimser ve aktif özne motivasyonunun tezahürüdür. Elbette Aktay'ın bu geniş ve özgür manevra alanı onun kavramlara pragmatik yaklaşımının da meyvesidir bir bakıma.

Aktay birkaç yerde postmodernizmin her ne kadar -modernizm gibi- ilerlemeci bir tarih anlayışını içinde barındırsa da esas itibariyle kavramın -özellikle küreselleşmeyle birlikte- zamandan ziyade mekâna, coğrafyaya göndermede bulunduğunu, “Dünyanın 
küre haline gelmiş olmasının bilinç üzerinde ayrı bir etkisi olduğunu"(s. 42) ifade ediyor. Fakat bu etkinin niteliği ve boyutlarına yeterince değinmediğini, argümanı kısmen muallakta bıraktığını söylemek gerekiyor.

\section{Modern Dünyada Sahicilik}

Modernleşme kavramının beraberinde getirdiği en dikkat çekici tartışmalardan biri de otantiklik/sahicilik sorunudur. -"Küreselleşme Çokkültürlülük ve Sahicilik" kitabında ele aldığı gibi- burada da Aktay 1srarla her tarihsel toplumsal bağlamın kendi başına otantik olduğunu vurguluyor ve bu da esasında özellikle Müslümanlara asr-1 saadet kavramına atfettikleri genel-geçer anlamın ötesinde bir pencere sunuyor. Bu yaklaşım aslında her dönemde özgül ve özgün toplumsal, siyasal pratiğin imkânını sağlıyor. Varlığın şimdiliği buradalığı, fenomenolojisi üzerine kafa yormuş Heidegger' den yaptığ alıntı Aktay'ın otantisite kavramına kattığı dinamik anlamı özetliyor: "Gökkubbe altında söylenmemiş yeni bir söz yoktur. Ama benim bunu şimdi ve burada söylüyor oluşum yeni değil midir?"(s. 2). Evet, her dönem, her bağlam otantiktir, fakat yazar yine de içinde yaşanılan zamanın -ister gurbet ve özlem duygularıyla olsun, ister üstünlük duygusuyla olsun- bir önceki zamanlardan çok farklı olduğuna dair algıya karşı da uyarıyor, bunun bir bakıma sünnetullahı anlamanın önünde engel olduğunu hatırlatıyor. Kısaca yazar, otantisite ve tekerrür arasında bir denge zemini sunuyor.

\section{Din Sosyolojisi: Klasik Yaklaşımlar}

Aktay din sosyolojisinin temel tartışmalarını ele alırken dinin kökeni ve tanımına dair yaklaşımları bugünün algı dünyasında somut güncel karşılıklarla ele alıyor. Dinin en yaygın tanım denklemi olarak kutsal ve profan ikiliği üzerinde durarak bir yandan da okuyucuyu modern dönem kutsallıklarımızı görmeye çağırıyor. Kurguladığımız dinsel (kutsal)-dünyevi ayrımların inandığımız dini ne derece toplumsal siyasal gerçeklikten uzaklaştırdığına işaret ediyor. Yanı sıra özellikle Durkheim'in dinin temeline dair incelemesinde ele aldığı totem düşüncesi üzerinden modern çağın sembolik sermaye araçlarına dikkat çekiyor.

\section{Din sosyolojisi- dini sosyoloji}

Aktay din sosyolojisi-dini sosyoloji ayrımı yaparak sanki başta üzerinde durduğumuz, inançlar ile bilimsel faaliyet arasındaki ince çiz- 
giyi belirginleştirmeye çalışıyor. Ne var ki bu ayrımın bizce epistemolojik açıdan sorunlu olduğunu ifade etmek gerekiyor. Aktay'a göre "din sosyolojisi incelediği dini davranışın doğruluğu veya yanlışlı̆̆ hakkında bir yargıda bulunmaz. Amacı dinsel anlayış ve sosyal değişim dinamikleri arasındaki ilişkileri ele almaktır" (s. 73). Dini sosyoloji ise "sosyolojiyi belli bir dinin perspektifinden ele almaktır" (s. 73). Kanaatimizce bu ayrım temelde modern bilimlerin ontolojik ve epistemolojik temellerini yok sayan ya da yansiz sayan bir bakış açısına götürür ki bu zaten Aktay'ın eleştirdiği bir varsayımdır. Bu tartışma daha önce de islam sosyolojisi/antropolojisi-islami sosyoloji/antropoloji ikilikleri üzerinden tartışılmış, bilginin İslamileştirilmesi çalışmalarının da ana sorunsallarından birini oluşturmuştur. Esasen bu tartışmalara son derece vakıf olan Aktay'ın bu önemli konuyu kitapta oldukça kısa ele alması kanaatimizce argümanlarını üzerine bina ettiği genel epistemolojik zemine de zarar vermiştir.

\section{Tanrı'yla İlişki Sosyal Eylem midir?}

Weber'in anlamacı (verstehen) sosyolojisi sosyal olguyu tanımada araştırmacının hazır teorik ve metodolojik kalıpların değil, sosyal aktörlerin söz konusu olgulara atfettikleri öznel anlamların temel alınması gerektiğini savunur. Sosyolojide ciddi teorik açılım sağlayan Weber'in bu perspektifi sosyal eylem kavramına da yeni bir boyut kazandırmıştır. Bu anlamda Aktay'ın Bryan Turner'den mülhem sorusu Tanrı ile olan ilişkinin sosyal eylem sayılıp sayılmayacağıdır ki ikisine göre de bu sorunun yanıtı olumludur. Tanrı'nın sosyal aktör olarak algılandığı bir toplumsallık, dinsel inancın gündelik yaşam pratiğiyle ilişki boyutunu ve kapsamını alabildiğine genişletmiş olmakla kalmıyor, aynı zamanda dinsel-din dışı ayrımının da ne derece muğlak ve geçirgen olduğunu göstermiş oluyor. Aktay bu iç içeliğin aslında tipik bir uygulaması olarak Amerika'da Mormonlar üzerine yürüttüğü saha araştırmasından epeyce söz ediyor ve okuyucuya on milyondan fazla mensubu olan, Utah Eyaleti Salt Lake City merkezli bu dinin toplumsal, ekonomik ve politik düzlemlerde örgütleniş biçimini detaylı olarak sunuyor.

Postmodern durum ve küreselleşme denilince ilk planda farklılıklar ve çoğulculuk akla geliyor elbette. Aktay'ın "eğer bu dünyada yalnız değilsek, bu dünyada tabiri caizse kendimize benzeyen insanlarla biz bize değilsek, bir ortak alan inşa etmek zorunluluğundan kaynaklanan insanlık durumu" olarak tanımladığ 1 "siyasal"ın 
en temel dinamiği kuşkusuz ortak gerçeklik algısının inşasıdır. Aktay mikro toplumsal ilişkiler düzleminde sosyal aktörlerin anlam dünyalarının nasıl biçimlendiğine, zihni kalıpların bazen otomatik bazen bilinçli olarak nasıl inşa edildiğine ışık tutan ufuk açıcı yaklaşımlar olarak Fenomenoloji ve Etnometodolojiye özellikle değiniyor. Fakat ne yazık ki bu iki yaklaşımın sosyal bilimciler tarafından uzun zamandır ihmal edildiğini, sunacakları açlımlardan mahrum kaldığımızı üzülerek ifade etmek gerekiyor.

\section{Kentleşme, Din ve Çoğulculuk}

Aktay'a göre şehirleşme ve din bağlamında en önemli gelişme “her dinin göreceli bir pozisyona hapsolmasıdır. Bu, mevcut çoğulcu kültür içinde herhangi bir inancın geçerliliğine karar verecek bir üst konumun mevcut olmadığının dramatik keşfidir" (s. 119). Aktay bu durumu "dinlerin çoğulcu bir potada eşitlenmesi, hakikat iddialarının ortadan kalkmas1, ... küresel anomi, ... sanayi kent toplumunun yarattığ sosyal psikolojinin bir hakikat düşüncesine katı olarak bağ 1 kalmaya karşı psikolojik bir baskı yapması, kısaca inançların gevşemesi olarak" okuyor (s. 128). Bununla beraber ilerleyen bölümlerde ortaya çıkan çoğul manzaranın sunduğu imkânlara, özellikle Müslümanların hakikat tekelciliğini törpüleme, daha genelde sivil toplum kültürünü yükseltme boyutuna da dikkat çekiyor. Ona göre "eskiden kendini dünyanın merkezi, hakikatin tek temsilcisi sayan tüm mezhepler, cemaatler ve gruplar, küreselleşme veya iletişimin kitleselleşmesi ölçüsünde başkalarının da hakikat iddiasında aynı şansa sahip olduğunu görmek zorunda kalmakta ve başkalarına tahammüllü olmanın bilincini edinmektedir. (s. 180)" Aktay'ın bu temennisi öznelliğin ve eleştirelliğin dikkat çekici biçimde temayüz ettiği İslamcı grupların postmodern ya da geçmodern çoğulcu atmosferde hakikatin mi kendilerine ait olduğunu, yoksa kendilerinin mi hakikate ait olduklarını ayırt edebileceklerine dair bir umudu da beraberinde taşıyor sanki.

\section{Gelenek - Değişim}

Aktay gelenek tartışmasında bizi içinde bulunduğumuz toplumsal bağlamda, inandığımız hakikatler demetinin ne ölçüde sahih ne ölçüde kurgu olduğunu düşünmeye çağırıyor. Gelenek ister yerleşik düzeni, ister Hobsbawn'cı bakışla kurguyu ifade etsin, temelde toplumsal davranıştaki sürekliliktir. Bizce Aktay'ın vurgusu bu sürekliliğin gerçekliğin ne kadarına tekabül ettiğinin her daim yeniden sorgulanarak öz/düşünümsel bir duyarlılıkla korunmasıdır. 


\section{Teoloji-Antropoloji Ayrumı}

Aktay, ilahiyat sosyolojisi başlığı altında Türkiye'de ilahiyatçıların toplumsal rollerini tartışırken eleştiri oklarından birini de teolojiye karşı antropolojiyi öneren ilahiyat çevrelerine yöneltiyor. Fakat bu yaklaşımın naifliğini vurgulayan Aktay aslında eleştirisini söz konusu ayrımın temel eksenine pek değinmeden sürdürüyor. Bu yönüyle eleştirisi eksik kalıyor. Teolojiye karşı antropolojinin önerilmesi yaratıcıya karşı insanın öncelenmesi, veya yaratıcıya verilen değerin insana verilen değere bağlı kılınmasından daha ziyade -ki bu yaklaşım esasında hümanizm tanımına daha uygundur- dinin aslında tam da antropolojik gerçekler üzerinden tanımlanması, bireysel, toplumsal, ekonomik, siyasal gerçekliğin ve pratiğin tüm veçheleriyle dinin mesajına mündemiç olmasıdır. Soyut dinsel çağrının somut insan gerçekliğine, pratik kaygı ve ihtiyaçlarına dokunabilmesidir. Bu aynı zamanda, dinsel-dindışı, kutsal-seküler ayrımını anlamsızlaştıran bir içkinliktir.

\section{Sivil Toplum Tartışmaları}

Aktay bu bölümde sivil toplum kavramına dair literatürü özetliyor ve sivil toplum - devlet ilişkisini bağımlılık, dışsallık ve karşıtlık boyutlarıyla tartışıyor. Din ve sivil toplum ekseninde ise tartışmayı Müslümanlar özelinde sürdürüyor. Aktay kavramın tarihsel süreç içinde edindiği anlamları sıralarken aynı zamanda kavramlara otantik, sabit anlamlar atfetmediğini, bu konuda pragmatik yaklaştığını kavramların anlam serencamını ve akıbetini "dilin kendi piyasasının şartlarına bıraktığını (s. 294)" söylüyor.

Aktay, sivil toplum kavramına kitabın değişik bölümlerinde farklı açılardan değinmiş görünüyor. Birkaç yerde tekraren vurguladığı noktalardan birisi sivil toplumun zorunlu olarak devlet karşıtı veya devlete muhalif anlamına gelmediğidir. Fakat diğer yandan "Hegel'e kadar uzanan çizgide aydınlanma düşünürlerinin önemli bir kısmının sivil toplumu devletle doğrudan ilişkili olmayan toplumsal alan olarak kavramsallaştırdıklarını" hatırlatıyor (s. 298). Yanı sıra sivil toplumun her zaman baskıcı yönetimlere karşı toplumun değişik kesimlerinin özgürlük arayışıyla alakalı olduğunu yazıyor. Başka yerde devlete karşı olmanın sivil toplumun tabiatında da var olan bir özelliği olduğunu ekliyor. Sivil topluma bireyi veya vatandaşı devlete karşı koruyan mekanizmanın adı olarak değiniyor (s. 399). Kanaatimizce Aktay'ın devlet sivil toplum ilişkisindeki kategorik karşıtlığa itirazının sebebi Türkiye'de sivil toplum 
tartışmalarının çoğunlukla devleti olumsuzlayan hatta şeytanlaştıran bir zeminde yürütülüyor olmasıdır. Aktay ise tersine, sivil toplum kavramını siyasal katılımla doğrudan ilişkilendiriyor ve sivil toplum kültürünün yükselişinin "ortak alanın inşasını amaçlayan tipik vatandaşlık davranışı (s. 382)" olarak "siyaseti", siyasal kültürü siyasal bilinci de yükselteceğinin altını çiziyor.

Kuşkusuz sivil toplum ve siyaset, günümüzde şiddet sarmalına hapsedilmeye çalışılan Müslümanların üzerinde hassasiyetle durmaları gereken kavramlardır. Yasin Aktay'ın Postmodern Kavşakta Din ve Sivil Toplum, bu anlamda biz Müslümanlara hem mensup olduğumuz inancın toplumsal siyasal çıarımlarına, hem de siyasetin imkân ve ufuklarına dair yeni bir perspektif sunuyor.

Kenan ÇAPIK

(Dr. Öğrencisi, ODTÜ, Sosyoloji Bölümü) 


\section{Milel ve Nihal \\ inanç, kültür ve mitoloji araştırmaları dergisi}

\section{YAYIN İLKELERİ}

1. Milel ve Nihal: İnanç, Kültür ve Mitoloji Araştırmaları Dergisi yılda iki kez, altışar aylık dönemler halinde yayımlanan bilimsel hakemli bir yayın organıdır.

2. Her yıl Haziran ve Aralık aylarında yayımlanır.

3. Yayın dili Türkçe ve İngilizce'dir.

4. Dergide değerlendirilmesi istenen metinler dergi@milelvenihal.org e-posta adresine gönderilmelidir.

5. Milel ve Nihal dergisinde telif makalelerin yanı sıra çeviri, sadeleștirme, edisyon kritik ve kitap değerlendirmesi çalışmaları yayımlanır.

6. Dergiye gönderilen makaleler başka bir yerde yayımlanmamış veya yayımlanmak üzere gönderilmemiş olmalıdır.

7. Yayımlanmak üzere gönderilen telif makaleler, Yayın Kurulu tarafından incelendikten sonra değerlendirilmeye uygun görülürse konunun uzmanı en az iki hakeme gönderilir ve her iki hakemden de olumlu rapor gelmesi halinde yayımlanır.

8. Hakemlerden biri olumsuz görüş belirttiği takdirde makalenin yayımlanıp yayımlanmamasına Yayın Kurulu karar verir.

9. Hakemlerden biri veya her ikisi "düzeltmelerden sonra yayımlanabilir" görüşü belirtirse gerekli düzeltmelerin yapılması için makale, yazarına iade edilir. Düzeltme yapıldıktan sonra hakemlerin uyarılarının dikkate alınıp alınmadığı Yayın Kurulu tarafından değerlendirilir.

10. Çeviri ve sadeleştirme yazılarında gönderiye, metinlerin orijinallerinin bir kopyası da taranarak eklenmelidir.

11. Dergiye gönderilen metin yayımlanmadı̆̆ında hakem raporları yazara gönderilerek karar bildirilir. Kitap değerlendirme yazılarının yayınına Yayın Kurulu karar verir.

12. Yazar gönderdiği metne, başlıca yayınlarını da içeren bir akademik özgeçmiş de eklemelidir. Ayrıca yazar makalesinde yer alan adının sonunda dipnot referansı vererek burada akademik ünvanını, bağlı bulunduğu Üniversite ve Fakülte adıyla Anabilim Dalını yazarak sonuna e-posta adresini eklemelidir. Akademik görevi bulunmayan yazar, varsa akademik ünvanıyla birlikte bağlı bulunduğu kuruma e-posta adresini eklemelidir.

13. Yayımlanmasına karar verilen makaleye yazarı tarafından İngilizce başlık, en çok 200 kelime İngilizce ve Türkçe özet eklenmelidir.

14. İngilizce yayımlanan makalelerin kaynakça kısmından sonra başlık ve anahtar kelimeler ile birlikte 7501000 kelimelik Türkçe geniş özet eklenmelidir.

15. Milel ve Nihal dergisinde yayımlanan yazıların dil, üslup ve içerik açısından yasal ve hukuki sorumluluğu yazarlarına aittir.

16. Yayımına karar verilen makaleler öncelikle matbu olarak basılacaktır. Her yeni sayı çıktığında bir önceki sayının tüm makaleleri PDF olarak www.milelvenihal.org sitesinde yayınlanacaktır.

17. Aşağıda açıklanan yazım ilkelerine ve biçimlendirmeye uyulmadan dergiye ulaştırılan yazılar, hakeme gönderilmeden önce düzeltilmesi için yazara iade edilir.

\section{YAZIM İLKELERI}

1. Yazllar, PC Microsoft Office Word (Word 97 veya daha ileri bir versiyonu) programında yazılmalı veya bu programa uyarlanarak gönderilmelidir. Metin sonuna kaynakça eklenmelidir. Gönderilen yazıların ekleriyle birlikte toplamı 7.000 kelimeyi (kitap tanıtım ve tenkit yazıları ile akademik içerikli kısa notların ise 1500 kelimeyi) aşmaması gerekir.

2. Sayfa düzeni: A4 boyutunda olmalıdır. Kenar boşlukları soldan $2,5 \mathrm{~cm}$, sağdan $2 \mathrm{~cm}$, üstten $2,5 \mathrm{~cm}$ ve alt$\tan 2 \mathrm{~cm}$ şeklinde ayarlanmalıdır.

3. Biçim: Metin kısmı Candara yazı tipi, 11 puntoyla, makale ismi dâhil bütün başlık ve alt başlıklardaki kelimelerin ilk harfleri büyük diğerleri küçük harflerle bold olarak; metnin tamamı 1,2 satır aralıkla, dipnotlar ise tek satır aralıkla ve 10 punto ile yazılmalıdır.

4. Yazarlar, makalelerinde Chicago ve APA dipnot gösterme sisteminden birisini kullanabilirler. Chicago dipnot gösterme sistemiyle yazılan makalelerin tüm dipnotları metin sonunda yer almalıdır. APA sistemini kullanan yazarlar ise dipnotlarda kullanılan referanslarla ilgili tam bilgileri (yani yazar, çalışmanın başlığı, basım yeri, yayınevi ve basım yılı gibi) metnin sonunda kaynakça olarak vermelidirler.

5. Chicago sistemindeki dipnotlarda aşağıda belirtilen kaynak gösterme usullerine uyulması gerekir:

a. Kitap: Yazar adı soyadı, eser adı (italik), çeviri ise çevirenin adı (çev.:), tahkikli ise (tahk.:), sadeleștirme ise (sad.:), edisyon ise (ed.: veya haz.:), sırasiyla baskı yeri: yayınevi, tarihi parantez içinde, cildi (örnek; c. IV), sayfası (s.), sayfadan sayfaya (ss.); yazma eser ise yazar adı, eser adı (italik), Kütüphanesi, numarası (no:), varak numarası (örnek, vr. 10b). Hadis eserlerinde varsa hadis numarası belirtilmelidir.

b. Makale; Yazar adı soyadı, makale adı (tırnak içinde), dergi veya eser adı (italik), çeviri ise çevirenin adı (çev.:), yayınevi, baskı yeri ve tarihi, cildi (örnek; c. IV), süreli yayın ise (örnek; sayı: 3), sayfası (s.).

c. Basılmış sempozyum bildirileri ve ansiklopedi maddeleri, makalenin referans veriliș düzeniyle aynı olmalıdır.

d. Dipnotlarda ikinci defa gösterilen aynı kaynaklar için; sadece yazarın soyadı veya meşhur adı, eserin kısa adı, cilt ve sayfa numarası yazılır.

e. Arapça eser isimlerinde, birinci kelimenin ve özel isimlerin baș harfleri büyük, diğerleri küçük harfler-le yazılmalıdır. Farsça, İngilizce, vb. diğer yabancı dillerdeki ve Osmanlı Türkçesi ile yazılan eser adlarının her kelimesinin baş harfleri büyük olmalıdır.

f. Ayetler sure adı, sure no / ayet no sırasına göre verilmelidir (örnek, el-Bakara, 2/10).

6. Dergimizde kullanılan bazı genel kısaltmalar: bakınız (bk.), karşılaştırınız (krş.), adı geçen eser (age), Diyanet Vakfi İslâm Ansiklopedisi (DİA), MEB İslâm Ansiklopedisi (İA), Kütüphane (Ktp.), numara (no:), ölümü (ö.), tarihsiz (ts.), aleyhi's-selam (s).

7. Makalelerde, bizzat makale için araștırılmış olmayan ve orijinal değeri bulunmayan istatistikî bilgilere ait şekilsel göstergelerin, haritaların ve görsel ürünlerin mümkün olduğunca kullanılmaması; lüzumu halinde istatistikî bilgilerin renkli sütunlar ya da şekiller yerine metin formu içinde rakamsal değerleri ile ifade edilmesi gerekir.

8. İnternet kaynakları, yayımlanması planlanan makaleler için iki özelliğiyle kullanılabilir: (i) Klasik bir metne yapılan atıfta internet kaynağı kullanılabilir; (ii) Çok güncel olan ve henüz matbû formu oluşmamış aktüel bilgi, rapor ve anket çalışmalarına işaret etmek için internet kaynağı kullanılabilir. Bu durumların dışında herhangi bir internet sitesi kesinlikle kaynak olarak gösterilemez. 


\title{
MİLEL VE NiHAL
}

inanç, kültür ve mitoloji araştırmaları dergisi

Cilt/Volume: 12 Sayı/Number: 2 Temmuz - Aralık / July - December 2015 ISSN: $1304-5482$

Bu dergi uluslararası EBSCO HOST Research Databases veri indeksi ve TÜBITAK-ULAKBİM Sosyal ve Beşeri Bilimler Veri Tabanı tarafından taranmaktadır.

\section{Sahibi / Owner}

Milel ve Nihal Eğitim, Kültür ve Düşünce Platformu Derneği adına Şinasi Gündüz

\author{
Yazı İşleri Sorumlusu / Legal Representative \\ Yasin Aktay
}

Editör / Editor

Şinasi Gündüz

Editör Yrd. / Co-Editor

Cengiz Batuk

Hakan Olgun

\section{Sayı Editörü / Editor of Issue \\ Mustafa Tekin}

Yayın Kurulu/ Editorial Board*

Alpaslan Açıkgenç, Ayaz Akkoyun, Yasin Aktay, Mahmut Aydın,

Cengiz Batuk, Şinasi Gündüz, İbrahim Kayan, Hakan Olgun, Necdet Subaşı,

Burhanettin Tatar

\section{Danışma Kurulu/Advisory Board*}

Baki Adam (Prof. Dr., AÜ); Mohd. Mumtaz Ali (Prof. International Islamic U. Malezya); Adnan Aslan (Prof.Dr., Süleyman Şah Ü.); Kemal Ataman (Doç.Dr., Uludağ Ü.); Mehmet Akif Aydın (Prof. Dr., Marmara Ü.); Yılmaz Can (Prof. Dr., OMÜ); Ahmet Çakır (Doç. Dr., OMÜ); Mehmet Çelik

(Prof. Dr., Celal Bayar Ü.); Waleck S. Dalpour (Prof. University of Maine at Farmington); İsmail

Engin (Dr., Berlin); Cemalettin Erdemci (Prof.Dr. YYÜ); Tahsin Görgün (Prof.Dr., 29

Mayıs Ü.) Ahmet Güç (Prof.Dr., Uludağ Ü.); Recep Gün (Doç. Dr., OMÜ); Ö. Faruk Harman

(Prof.Dr., Mar.Ü.); Erica C.D. Hunter (Dr., Cambridge U.); Mehmet Katar (Prof. Dr., A.Ü.);

Mahmut Kaya (Prof. Dr., İ.Ü.); Sadık Kılıç (Prof.Dr., Atatürk Ü.); Şevket Kotan (Y.Doç.Dr., İ.Ü.);

İlhan Kutluer (Prof.Dr., Mar. Ü.); George F. McLean (Prof. Catholic Univ., Washington DC); Ahmet Yaşar Ocak (Prof. Dr., Hacettepe Ü.); Jon Oplinger (Prof. University of Maine at Farmington); Ömer

Özsoy (Prof.Dr., Frankfurt U.); Roselie Helena de Souza Pereira (Mestre em

Filofia-USP; UNICAMP Brasil); Ekrem Sarıkçıŏlu (Prof.Dr., SDÜ); Hüseyin Sarığlu (Prof.Dr.,

İ̈); Bobby S. Sayyid (Dr. Leeds U.); Mustafa Sinanoğlu (Prof.Dr., 29 Mayıs Ü.); Mahfuz Söylemez

(Prof.Dr. İ̈); Necdet Subaşı (Y.Doç.Dr., DİB); Bülent Şenay (Prof.Dr., UÜ); İsmail Taşpınar

(Prof.Dr. Mar.Ü.); C. Sadık Yaran (Prof.Dr., OMÜ); Ali Murat Yel (Prof.Dr., Fatih Ü.); Hüseyin Yılmaz (Doç.Dr., YYÜ); Ali İhsan Yitik (Prof. Dr., DEÜ)

* Soyadına göre alfabetik sıra / In alphabetical order

Kapak ve Sayfa Tasarımı / Cover \& Page Design İnan Avc1

Baskı / Publication

Ladin Ofset - İstanbul, Nisan 2016

2.Mat. Sit. 3 NB 15 Topkapı İstanbul / İsmail Tüz 02125012418

Yönetim Yeri / Administration Place

Milel ve Nihal Eğitim, Kültür ve Düşünce Platformu Derneği

Fevzipaşa Cad. Şehit Mehmet Sarper Alus Sok. No: 5, K.: 3, Tel: (0212) 5339731 Fatih/İstanbul www.milelvenihal.org e-posta: dergi@milelvenihal.org

Milel ve Nihal yılda iki sayı olarak altı ayda bir yayımlanan uluslararası hakemli bir dergidir. Milel ve Nihal'de yayımlanan yazıların bilimsel ve hukuki sorumluluğu yazarlarına aittir. Yayım dili Türkçe ve İngilizce'dir. Yayımlanan yazıların bütün yayın hakları Milel ve Nihal'e ait olup, yayıncının izni olmadan kısmen veya tamamen basılamaz, çoğaltılamaz ve elektronik ortama taşınamaz. Yazıların yayımlanıp yayımlanmamasından yayın kurulu sorumludur. 


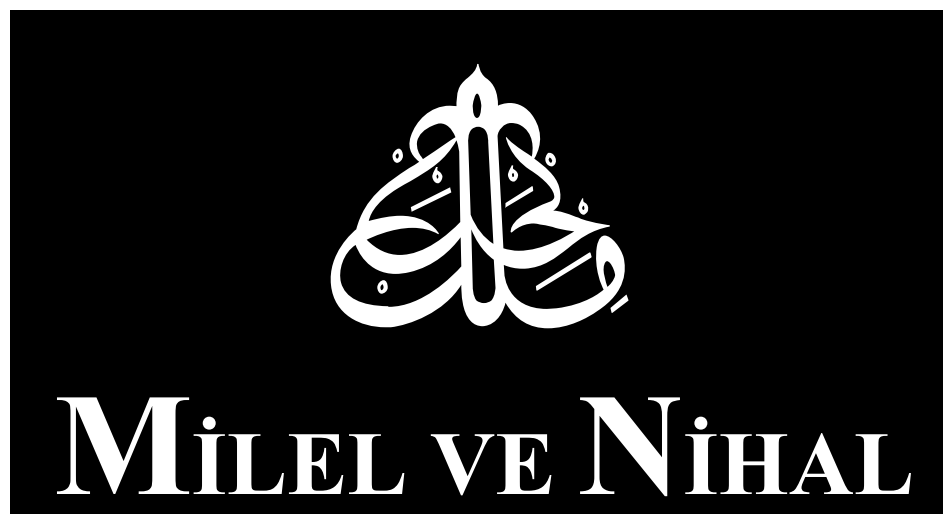

inanç, kültür ve mitoloji araştırmaları derģisi

ISSN: 1304-5482

DIN VE POSTMODERNIZMM

Cilt/Volume: 12 Sayı/Number: 2

Temmuz - Aralık / July - December 2015 
